doi: 10.12957/childphilo.2019.36602

\title{
corpo, técnica e jogo na infância: notas da teoria crítica de theodor w. adorno $^{1}$
}

\author{
mara salgado ${ }^{2}$ \\ universidade estadual paulista júlio mesquita filho, brasil \\ orcid id: https:/ / orcid.org/0000-0001-5795-2561
}

\section{resumo}

O artigo apresenta considerações acerca da infância na Teoria Crítica de Theodor Adorno, com foco nas reflexões acerca do corpo, da técnica e do jogo que marcam a infância como um outro da razão. A infância é retratada por Adorno como um lugar das primeiras utopias, a pátria ansiada e, desde sempre inabitada, que se torna falsa a qualquer tentativa de resgate, mas ilumina o desejo outrora experimentado num jogo com o corpo e o pensamento, o sonho e a realidade, a experiência de outra ordem da razão que alimenta a memória da natureza animal do humano, sem, contudo, estar isenta das forças históricas dominantes que incidem sobre os processos de subjetivação. Tais reflexões partem de escritos de Adorno e daquilo que seus diálogos com interlocutores, como Walter Benjamin, Freud e Huizinga, podem suscitar na análise do tema. Num segundo movimento do texto, para a compreensão dos limites e potencialidades da dinâmica atual da brincadeira mediada pela tecnologia, tomou-se como exemplo alguns estudos acerca da realidade virtual, em especial, dos jogos eletrônicos em contraposição com a teoria de Huizinga sobre o caráter sagrado no jogo. Conjecturas sobre como o contato com a realidade está danificado já na infância pela relação com a tecnologia, estabelecendo a busca por satisfação imediata, podem revelar a qualidade da atenção que as crianças recebem nos processos educativos e dar pistas sobre a crescente manifestação de transtornos sócio afetivos, que culminam na preferência por dispor o tempo e o corpo às brincadeiras eletrônicas em detrimento do contato real com as outras crianças.

palavras-chave: infância; corpo; jogo; jogos eletrônicos; teoria crítica.

\section{body, technique and play in childhood: notes on the critical theory of theodor w. adorno}

abstract

This paper discusses the status of about childhood in Theodor Adorno's critical theory, focusing on his reflections on the body, on technique and on play that mark childhood as another form of reason. Childhood is portrayed by Adorno as a place of the "first utopia," that longed for and permanently uninhabited homeland that resists any rescue attempt, but illuminates the desire we once experienced, in a play between body and thought, dream and reality. Adorno's child evokes the experience of another order of reason that feeds on the memory of the human's animal nature, without, however, being exempt from the dominant historical forces that affect the processes of subjectivation. These reflections start with the writings of Adorno and what his dialogues with interlocutors, such as Benjamin, Freud, and Huizinga, contribute to the analysis of the topic. In the second part

\footnotetext{
$1 \mathrm{O}$ artigo apresenta parte dos estudos realizados na tese de doutoramento, realizada com financiamento da Capes no Programa de Pós-Graduação em Educação da Universidade Federal de Santa Catarina (UFSC), sob a orientação do Prof. Dr. Alexandre Fernandez Vaz, intitulada Entrelaçamento de amor e do pensamento na infância em Theodor W. Adorno: um estudo sobre mimese, imaginação e memória (SALGADO, 2017).

2 E-mail: marasalgado.ms@gmail.com
} 
of the article, in an effort to understand the potential and the limits of technologicallymediated play, we discuss several studies of virtual reality, especially electronic games. Conjectures about how contact with reality is already damaged in childhood by the relationship with technology, which establishes a desire for instant gratification, suggest a critique of the quality of attention that children receive in their education, and provide clues about the increasing appearance of socio-affective disorders, which culminate in the preference to dispense with time, the body, and real contact with other children in favor of electronic play.

key words: childhood; body; technique; play; eletronic games; critical theory.

\section{cuerpo, técnica y juego en la infancia: notas de la teoría crítica de theodor w. adorno}

resumen

El artículo presenta consideraciones acerca de la infancia en la Teoría Crítica de Theodor Adorno, con foco en las reflexiones acerca del cuerpo, de la técnica y del juego que marcan la infancia como otro de la razón. La infancia es retratada por Adorno como un lugar de las primeras utopías, la patria ansiada y, desde siempre inhabitada, que se vuelve falsa a cualquier intento de rescate, pero ilumina el deseo antaño experimentado en un juego con el cuerpo y el pensamiento, el sueño y la realidad, la experiencia de otro orden de la razón que alimenta la memoria de la naturaleza animal de lo humano, sin embargo, dejar exento las fuerzas históricas dominantes que inciden sobre los procesos de subjetivación. Tales reflexiones parten de escritos de Adorno y de lo que sus diálogos con interlocutores, como Walter Benjamin, Freud y Huizinga, pueden suscitar en el análisis del tema. En un segundo movimiento del texto, para la comprensión de los límites y potencialidades de la dinámica actual del juego mediado por la tecnología, se tomaron como ejemplo algunos estudios acerca de la realidad virtual, en especial, de los juegos electrónicos en contraposición con la teoría de Huizinga sobre el carácter sagrado en el juego. Conjeturas sobre cómo el contacto con la realidad está dañado ya en la infancia por la relación con la tecnología, estableciendo la búsqueda por satisfacción inmediata, pueden revelar la calidad de la atención que los niños reciben en los procesos educativos y dar pistas sobre la creciente manifestación de trastornos socio afectivos, que culminan en la preferencia por disponer el tiempo y el cuerpo a los juegos electrónicos en detrimento del contacto real con los otros niños.

palabras claves: infância; cuerpo; técnica; juego; juegos eletrônicos; teoría crítica. 
corpo, técnica e jogo na infância: notas da teoria crítica de theodor w. adorno ${ }^{3}$

Este artigo num primeiro movimento apresenta considerações acerca da infância com base na Teoria Crítica de Theodor Adorno e daquilo que seus diálogos com interlocutores, como Walter Benjamin, Freud e Huizinga, podem suscitar nas análises dos temas do corpo, da técnica e do jogo, que marcam a infância como um outro da razão. Num segundo movimento, tais reflexões tensionam o caráter sagrado do jogo, que segundo Huizinga envolvem o corpo e o pensamento, o sonho e a realidade, a experiência dessa outra forma de operar da razão, com os limites e potencialidades da dinâmica atual da brincadeira mediada pela tecnologia, em especial, por meio dos jogos eletrônicos e suas implicações no contato com a realidade.

Depois do período de exílio que possibilitou a um intelectual judeu sobreviver à exterminação nazifascista na Alemanha de Hitler, Adorno responde à pergunta sobre por que retornou à Alemanha, dizendo: "Sencillamente porque deseaba regresar al lugar en el que había pasado mi infancia, y en definitiva porque siento que en la vida uno no hace sino intentar recobrar de alguna forma su infancia" (CLAUSSEN, 2006, p. 30).

No livro Consignas, Adorno refere-se à infância como "aquello que determinó mi especificidad hasta en lo más íntimo" (Apud CLAUSSEN, 2006, p. 30).

Assim como nestas declarações, a infância é retratada em outras passagens da obra de Theodor W. Adorno por um lado como um lugar das primeiras utopias, a pátria ansiada e, desde sempre inabitada, que se torna falsa a qualquer tentativa de resgate, mas ilumina o desejo outrora experimentado num jogo com o corpo e o pensamento, o sonho e a realidade, a experiência de outra ordem da razão - mais mimética e imaginativa, que alimenta a memória da natureza animal do humano -, sem, contudo, estar isenta das forças históricas dominantes que

\footnotetext{
${ }^{3} \mathrm{O}$ artigo apresenta parte dos estudos realizados na tese de doutoramento, realizada com financiamento da Capes no Programa de Pós-Graduação em Educação da Universidade Federal de Santa Catarina (UFSC), sob a orientação do Prof. Dr. Alexandre Fernandez Vaz, intitulada Entrelaçamento de amor e do pensamento na infância em Theodor W. Adorno: um estudo sobre mimese, imaginação e memória (SALGADO, 2017).
} 
incidem sobre os processos de subjetivação. Por outro lado, e tirando proveito dessa razão que não abandonou sua intimidade com a natureza, a infância é reconhecida por Adorno como o espaço e o tempo propícios para as tentativas de combater a barbárie desde seus primeiros indícios.

O lar, a pátria da infância, já é para Adorno a expressão dialética do pensamento esclarecido que resguarda momentos de resistência ao amparar na subjetividade, não totalmente reificada, momentos racionais e irracionais (VAZ, 2006). Ou seja, o pensamento na infância ao alcançar certa fruição mimética e imaginativa apresenta também as contradições que marcam a razão esclarecida, entretanto, sem falseá-las, nem tanto por autenticidade, mas porque o corpo ainda não domesticado - brinca, mimetiza e, assim, transforma por meio do jogo o conteúdo ideológico social que com o passar dos anos aprendemos a justificar, geralmente, negando-o.

Ao contrário da ingênua ideia de que as crianças são naturalmente autênticas, Adorno (1951/1992), que não se enganava a respeito de que autenticidade e verdade não se equivalem, considerava que

[...] a insistência na verdade acerca de si mesmo, mostra constantemente, já nas primeiras experiências conscientes da infância, que os impulsos sobre os quais se reflete não são lá muito "autênticos". Eles contêm sempre um pouco de imitação, de jogo, de vontade de ser diferente. (ADORNO, 1951/1992, p. 134-135, aspas no original).

$\mathrm{O}$ jogo que abre passagem para imaginar o novo, escapando momentaneamente das pressões da realidade, só é possível quando se reconhece o sempre igual dos dias. Assim como quando a criança retorna das férias imaginando que encontraria outro lar, conforme escreveu Adorno (1951/1992):

À criança que regressa das férias, o lar parece novo, fresco, em festa. Mas aí nada mudou desde que ela o deixou. O simples esquecimento do dever, ao qual exorta cada móvel, cada janela, cada lâmpada, restaura a paz sabática, e por alguns minutos, na tabuada de salas, quartos e corredor, a gente está em casa de um modo tal que, a vida inteira, só o afirma a mentira. Não é de outro modo que, um dia, o mundo há de aparecer, sem mudanças quase, sob a luz incessante de seu feriado, quando não estiver mais sob a lei do trabalho e quando a quem torna à casa o dever for tão leve quanto o foi o jogo nas férias. (ADORNO, 1951/1992, p. 97).

Este ambiente de certa promessa de reconciliação entre o estranho e o familiar, a realidade e o abrigo, que Adorno apresenta, bem como seu amigo e parceiro intelectual Walter Benjamin tanto escreveu, traduz a experiência da 
infância do final do período burguês. Como é amplamente discutida, a partir dos estudos de Philippe Ariès ${ }^{4}$, a noção de infância tal como a categoria social com especificidades distintas da idade e da vida adulta que conhecemos, nasce com o estabelecimento do individualismo burguês por volta do século XVIII, cuja formação cultural dos indivíduos busca atender às expectativas de felicidade e emancipação contidas no ideal iluminista.

Por certo, as transformações sociais ocorridas ao longo da história não devem ser ignoradas, no entanto, a radicalidade do pensamento dialético dos autores da Teoria Crítica da Sociedade elucidou as premissas da razão esclarecida - do Iluminismo -, cujo desenvolvimento se atrelou ao sistema de dominação capitalista que ainda não foi superado até os dias atuais. Portanto, o núcleo de verdade temporal da perspectiva da Teoria Crítica no que tange às especificidades da infância, encontra ressonâncias no presente, tanto por parte dos conteúdos psicossociais recalcados filogeneticamente e ontogeneticamente e, por isso, persistentes nos processos de transmissão da cultura, quanto porque a lógica de desapropriação da experiência (intelectual e sensível) engendrada pelo sistema capitalista não foi enfraquecida, mas operacionalizada pela práxis social.

Ser criança no início dos anos de 1900, certamente era muito diferente do que ser criança nos dias atuais, contudo, qualquer observador interessado presenciará nas crianças comportamentos como: brincar com o próprio corpo, imitar pessoas, coisas e situações, jogar com a linguagem, perguntar insistentemente sobre diversos assuntos, pedir repetidamente pela mesma história ou brincadeira, se encantar mais com as embalagens vazias do que com os conteúdos dos presentes, iniciar pequenas coleções, tocar a terra, o barro, a comida e os objetos proibidos com mais ou menos a mesma sensação escrita por Benjamin (2002) em Criança lambiscando

Pela fresta do guarda-comida entreaberto sua mão avança como um amante pela noite. Uma vez familiarizada com a escuridão, tateia em busca de açúcar ou amêndoas, uva passas ou compotas. E assim como o amante abraça a sua amada antes de beijá-la, da mesma forma o tato tem um encontro preliminar com as guloseimas antes que a boca as saboreie. (BENJAMIN, 2002, p. 105).

\footnotetext{
${ }^{4}$ ARIÈS, P. História social da infância e da família. Tradução: D. Flaksman. Rio de janeiro: LCT, 1978. 
Dentre as possibilidades que a infância resguarda, esse tato desbravador dos objetos e espaços do mundo talvez seja a lembrança atualizada a cada geração de um tempo para a experiência que perdemos ao longo da vida. $O$ conceito benjaminiano de experiência (Erfahrung), com o qual Adorno parece compartilhar, se depreende, antes de tudo, da possibilidade de se perder nos objetos do presente e, por isso, se conectar com a tradição, comunicando a história do geral que compõe o momento particular e que na infância se expressa na efemeridade do instante (SELIGMANN, 2010). A experiência que se encontra enfraquecida nos tempos modernos pelos impedimentos para a fruição entre o particular e o universal, bem como a narração deste momento, se torna possível para a criança quando o corpo (os sentidos) permite certa materialização do movimento mimético ao transformar brinquedos e brincadeiras num ritmo que conta com a repetição e "não se abrevia o tempo, mas dele se dispõe com intensidade" (VAZ, 2010, p. 39).

Na medida em que o ritmo da máquina passou a ordenar a consciência em benefício do desenvolvimento tecnológico e, obviamente, econômico que despontava com a modernidade, as possibilidades de se ter experiências, de fruição no tempo e espaço, tornaram-se empobrecidas e foram substituídas pelo ritmo das vivências cada vez mais automáticas que contribuíram para um estado de consciência em choque ${ }^{5}$, a condição moderna para o esclarecimento.

Na perspectiva da Teoria Crítica da Sociedade, na infância a experiência não conta prioritariamente com a orientação da razão esclarecida, ela é antes um outro da razão que o esclarecimento deseja controlar para manter domesticada a natureza humana, os vestígios da face animal que lembram que a racionalidade não tem tudo sob controle como deseja dissimular. Se o esclarecimento é a possibilidade para o sujeito de, por meio da razão, libertar-se do medo e tornar-se

\footnotetext{
5 O estado de consciência em choque diz respeito às análises de Benjamin (1939/1989) acerca da correlação freudiana entre consciência e memória, segundo a qual o sistema percepção-consciência na tentativa de se proteger dos excessivos estímulos do mundo externo organiza uma espécie de barreira que filtra as informações, deixando passar os traços mnêmicos que serão armazenados pela memória. Segundo Benjamin (1939/1989), diante de constantes e intensas excitações da sociedade moderna, o aparelho psíquico sofre um choque traumático que põe a consciência em alerta, se defendendo contra as informações do mundo externo e diminuindo o armazenamento dos traços mnêmicos e, desse modo, enfraquecendo a memória, material inseparável da experiência.
} 
senhor de si mesmo, conforme o argumento kantiano retomado na Dialética do esclarecimento, para a criança o senhor de sua pré-razão, o mediador do pensamento, é o próprio corpo.

O corpo é o primeiro brinquedo, o objeto que apresenta o prazer e o desprazer ao eu e, assim, se constitui como mediação nas relações consigo próprio, com o outro e com o mundo. É no corpo, em cada órgão sensorial, que a vida vai se materializando numa tensão travada entre o domínio da natureza e a humanidade, relação que, segundo Benjamin (2012a), consiste o domínio da técnica. Neste ponto deve-se acrescentar a consideração de Adorno (1953/1986) de que somente como resultado da falsa consciência a técnica pode ser compreendida separada da sociedade, em antagonismo com o espírito. Ela é meio de transformação da natureza em favor dos indivíduos, e de seu progresso depende o progresso da civilização. Contudo, se a técnica é tomada como finalidade última da humanidade desfigura-se em fetiche, isto se deu na esfera da produção do conhecimento quando a ciência passou a supervalorizar o método em detrimento do pensamento, invertendo a relação entre meios e fins e, neste percurso, se opondo à sensibilidade que também compõe o conhecimento. Desse modo, o fetiche da técnica se tornou o simulacro da razão na orientação das relações entre os indivíduos e o mundo, estabelecendo uma administração tecnológica da sociedade, quanto a isto sim Adorno ao longo de sua vida não reservou críticas, principalmente, por entender que sob o véu tecnológico as possibilidades para que o pensamento não se restrinja aos mecanismos de defesa da consciência coisificada 6 ficam sobremaneira dificultadas.

Entende-se que a relação entre corpo e técnica marca a infância em processos indissociáveis, mas que podem ser compreendidos a partir de pontos distintos. O primeiro, que não é o caso de aprofundamento neste artigo, diz respeito às técnicas de dominação social empregadas para a repressão das pulsões

\footnotetext{
${ }^{6}$ Quando o trabalho passa a ter a forma da quantidade de valor de seu produto, converte-se ilusoriamente a relação entre pessoas, que revelam as inscrições sociais, em relações sociais entre os produtos, entre coisas (Marx, 1867/1988). Adorno (1971/1995) em Educação após Auschiwitz refere-se à consciência coisificada como "sobretudo uma consciência que se defende em relação a qualquer vir-a-ser, frente à qualquer apreensão do próprio condicionamento, impondo como sendo absoluto o que existe de um determinado modo" (p.132). Vale a lembrança de que tais características são precursoras do preconceito e do fascismo.
} 
eróticas infantis, em especial, por meio de uma educação autoritária, primeiramente da família e depois da escola, que culminou (filogeneticamente e ontogeneticamente) no narcisismo e no aprendizado do sacrifício, da renúncia e da obediência, em outras palavras, no amor-ódio pelo corpo, cuja expressão encontrase no masoquismo e sadismo entrecruzados ${ }^{7}$.

Tal argumentação sustenta-se nos diálogos com a psicanálise freudiana quando Adorno (CANEVACCI, 1981) se referiu às bases para a irreflexão e o autoritarismo - elementos da racionalidade tecnológica - na constituição da psicologia dos sujeitos, difundidas pelos processos educacionais por meio da frieza e do excesso da disciplina.

O segundo refere-se à assimilação do fetiche da técnica na formação da subjetividade na infância, cuja indústria cultural $^{8}$ se incumbe de realizar por meio dos processos de produção e de consumo de seus produtos.

Partindo de qualquer um dos pontos, encontram-se as faculdades do pensamento que atuam com mais força na infância, a saber: da mimese, da imaginação e da memória. Tais faculdades despontam mais próximas à natureza e ora por meio da brincadeira e do jogo inventam brechas de resistência frente à reificação da realidade, ora são falseadas e capturadas pelos processos de despersonalização da indústria cultural. Nesse sentido, pode-se dizer que as três faculdades resguardam pontos de entrelaçamentos da natureza e da cultura no

\footnotetext{
7 Para Freud (1905/1976), a dinâmica pulsional no período da infância, em que a sexualidade deixa de ser latente para ser vivenciada na relação com o próprio corpo (autoerotismo), é o que põe em movimento a atividade intelectual da criança. A partir da curiosidade, da imaginação e da memória de um resto de afetividade (o ventre da mãe), as pulsões sexuais passam a mover-se em direção aos primeiros objetos de amor (as zonas erógenas do próprio corpo e a relação com os pais), que serão reencontrados ao longo da vida psíquica, contudo, em formas modificadas. De modo sucinto, pode-se dizer que a repressão das pulsões sexuais desde a infância, engendrada pelas normas morais civilizatórias, obstrui a afetividade entre as pessoas, contribuindo para um ambiente psíquico propício para a agressividade contra si mesmo (masoquismo) e contra os outros (sadismo) como resposta ao movimento de autodefesa cujo investimento afetivo volta-se ao próprio eu (narcisismo).

8 Adorno (1963/1986) esclarece que ao cunhar o termo Indústria Cultural, ele e Horkheimer pretendiam ressaltar a diferença entre os produtos de uma sociedade massificada que estabelecem a padronização como modo de vida, das expressões da cultura de massa ou arte popular. Para tal diferenciação, os autores discorrem sobre os mecanismos de ilusão impregnados nos meios de produção e sua difusão, cuja técnica ocupa o lugar central como provedora do sistema econômico, que por sua vez, se estrutura de cima para baixo para juntar segmentos diferenciados socialmente, igualando-os na constituição e solidificação desse sistema (SALGADO; FRANCISCATTI, 2011).
} 
que se refere ao pensamento e ao corpo reificados, mas também no que está para além da reificação.

Pode-se ler em Horkheimer (1946/2002, p. 48) que “a reificação é um processo cuja origem deve ser buscada nos começos da sociedade organizada e do uso de instrumentos". Com essa afirmação, Horkheimer indica que a relação dos indivíduos com a técnica é precursora no processo de formação do indivíduo, que por meio da transformação da natureza empreendeu a dominação do corpo e do pensamento em nome da autoconservação.

Não é exagero dizer que todo o propósito pedagógico da educação infantil tem por base o domínio do corpo, de modo mais progressivo quando considera na infância a especificidade da experiência espacial e temporal, que se manifesta em grande parte através da brincadeira, e regressivo quando investe excessivamente no controle dos elementos mais próximos à natureza - em especial, do mais arcaico: a mimese - no ajustamento dos corpos em benefício da mera adaptação. Em última instância tal controle dificulta o tempo e o espaço para a brincadeira, a fruição no jogo, a experiência.

No que se refere às brincadeiras infantis, Adorno (1951/1992) considerava que a dominação social não é suprimida da percepção da criança no momento da brincadeira. Ao contrário do adulto que ao resignar-se com o mundo da supremacia das mercadorias perde a possibilidade de tal percepção, a criança é capaz de apreender "a contradição entre o fenômeno e a fungibilidade [...] e tenta a ela se subtrair" (ADORNO, 1951/1992, p. 200). Vale dizer, que à criança interessa mais o valor de uso que o brinquedo pode lhe proporcionar. Por meio do jogo a criança confronta o valor de troca com o valor de seu uso, desfazendo-se da utilidade designada para o brinquedo.

Está escrito no aforismo Lojinha de brinquedo:

Precisamente na medida em que despoja as coisas que manipula de sua utilidade mediatizada, a criança busca salvar, em seu trato com elas, o que as torna benéficas aos homens e não à relação de troca, que deforma igualmente homens e coisas. O caminhãozinho não vai a nenhum lugar, e os minúsculos barris que transporta estão vazios; todavia, permanecem fies à sua destinação não a exercendo, não participando do processo de abstração que nivela neles aquela determinação, mas ficam imóveis como alegorias daquilo para que existem especificamente. Dispersos, decerto, mas não absorvidos, aguardam para ver se a sociedade apagará um dia o 
estigma social que carregam, se o processo vital entre o homem e as coisas, a práxis, deixará de ser prática. (ADORNO, 1951/1992, p. 200).

Tal percepção sensível de Adorno indica um tempo de esperança resguardado na infância de que o mundo possa, um dia, se livrar da dominação empreendida socialmente, que submete a razão aos meios de produção (invertendo os fins e os meios), instrumentalizando-a em racionalidade tecnológica. Tal esperança de superar o esquema prático encarnado nos objetos habita o pensamento de Adorno, em especial, no que diz respeito à reivindicação de que o conceito não seja abolido do pensamento para que o objeto não se torne subserviente ao sujeito. Segundo o "modelo adorniano de uma salvação dos objetos", mencionado por Seligmann-Silva (2010, p. 86), a diferenciação entre sujeito e objeto, tão fundamental ao pensamento crítico ${ }^{9}$, necessita de uma "delicada distância", uma "contemplação não violenta" que impulsione à superação da dominação ao rearticular "as relações hierárquicas entre o homem e a natureza, as minorias e a dominação" (SELIGMANN-SILVA, 2010, p. 86).

Talvez possa ser dito, que o germe de tal tentativa de salvar os objetos da dominação existente desponta na criança que ainda não sabe bem o que é o real, mas se movimenta na apreensão do jogo que, conforme será tratado mais adiante, parece conter um momento estético conciliador da mimese, da imaginação e da memória, capaz de apaziguar razão e sensibilidade. Na continuação do aforismo citado acima Adorno (1951/1992) escreveu:

\begin{abstract}
A irrealidade dos jogos anuncia que o real ainda não o é. Eles são exercícios inconscientes para a vida justa. A relação das crianças com os animais repousa por completo sobre o fato de que a utopia se mascara em criaturas às quais Marx sequer concede que produzam trabalhando maisvalia. Na medida em que existem sem nenhuma tarefa a realizar que seja do conhecimento dos homens, os animais representam como expressão, por assim dizer, seu próprio nome, o que pura e simplesmente não pode ser trocado. Por isso as crianças os amam tanto e ficam a contemplá-los. Eu sou um rinoceronte, significa a figura de um rinoceronte. Os contos e as operetas conhecem essas imagens, e a ridícula pergunta daquela mulher: "Como é que sabemos que Órion se chama de fato Órion?" eleva-se às estrelas (ADORNO, 1951/1992, p. 200, aspas no original).
\end{abstract}

Desse modo, a relação entre sujeito e objeto na infância contém um momento de certa salvação ao possibilitar a fruição na imagem dos objetos que o

\footnotetext{
9 Seligmann-Silva (2010) lembra: "Para Adorno, o estado de indiferenciação entre sujeito e objeto é tão pernicioso quanto o da sua total separação, pregada pelo positivismo. A indiferenciação corresponde justamente ao mundo do mito" (p. 87).
} 
pensamento esclarecido - o saber sobre a natureza - recalcou em favor de dominar a natureza e aos homens, tornando-se ele mesmo o poder a serviço da dominação. “A técnica é a essência desse saber, que não visa conceitos e imagens, nem o prazer do discernimento, mas o método, a utilização do trabalho de outros, o capital", disseram Adorno e Horkheimer (1947/1985, p. 18) na Dialética do esclarecimento.

Se o que faz a figura do rinoceronte aparecer quando a criança se apresenta como o rinoceronte diz respeito à faculdade da mimese, não se pode deixar de mencionar que neste movimento também estão a imaginação que põe a imagem em ação, e a memória que oferece os elementos conhecidos que compõem a imagem.

Entretanto, deve-se perguntar se os objetos e os jogos que circundam as crianças, desde a mais tenra infância na atual sociedade tecnológica, oferecem algum espaço para a experiência, de modo que a imagem seja composta no movimento das faculdades da mimese, da imaginação e da memória, ou se eles mesmos - os objetos e os jogos - já as capturaram como meros meios de exibição técnica.

\section{brincadeiras e jogos em tempos de tecnologia}

Os brinquedos, os jogos e as relações estabelecidas na infância, tal como analisaram Adorno (1971/1995; 1951/1992), e mais explicitamente Walter Benjamin (1994; 2002; 2002a), sofreram modificações radicais e apesar de na infância coabitarem os elementos que marcam o brincar como a forma de operar do pensamento da criança e as relações com os novos brinquedos tecnológicos, não se pode deixar de confrontar a materialidade atual que suporta as brincadeiras infantis.

Ao que parece, as condições materiais que recebem as crianças no mundo hoje em dia não se diferem muito, em termos de acesso, daquelas vivenciadas pelos adultos, nem quanto às relações de consumo ensinadas pelos próprios brinquedos - em especial os jogos eletrônicos -, tampouco pelo uso dos produtos, os smartphones, tablets e notebooks, que dependem de alta tecnologia para a 
comunicação nas relações interpessoais e pedagógicas que compõem a infância atual.

Se Adorno (1971/1995) já considerava em seu tempo que a relação com a técnica era excessiva e contribuía para a permanência do estado de coisificação da consciência dos indivíduos, suas análises só podem ser reverenciadas nos dias de hoje. Em Educação após Auschiwtz pode ser lido:

No que diz respeito à consciência coisificada, além disto, é preciso examinar também a relação com a técnica, sem restringir-se a pequenos grupos. Esta relação é tão ambígua quanto a do esporte, que, aliás, tem afinidade. Por um lado, é certo que todas as épocas produzem as personalidades - tipos de distribuição de energia psíquica - de que necessitam socialmente. Um mundo em que a técnica ocupa uma posição tão decisiva como acontece atualmente, gera pessoas tecnológicas, afinadas com a técnica. Isto tem a sua racionalidade boa: em seu plano mais restrito elas serão menos influenciáveis, com as correspondentes consequências no plano geral. Por outro lado, na relação atual com a técnica existe algo de exagerado, patogênico. Isto se vincula ao "véu tecnológico". (ADORNO, 1971/1995, p. 132, aspas no original).

$\mathrm{O}$ "atualmente" da citação apenas prenunciava as patologias que estariam por vir com o desenvolvimento da tecnologia no século XXI, em termos quantitativos no que se refere aos inúmeros produtos tecnológicos dos quais dispõem os indivíduos cotidianamente, e qualitativos quanto ao refinamento da relação entre os sentidos humanos e o funcionamento da tecnologia.

Nos dias atuais, as patologias vinculadas ao uso compulsivo da tecnologia, principalmente na infância e na adolescência não são suposições. Estudos como o de Picon et al (2015) apresentam as consequências negativas da dependência de tecnologia, analisadas em clínicas psicoterápicas, quanto à saúde física, aos relacionamentos interpessoais e ao desempenho intelectual. A dependência de tecnologia atualmente é caracterizada por um transtorno psicológico, cuja inabilidade de controlar o uso de tecnologia, via internet, jogos eletrônicos, redes sociais e smartphones, acarreta em prejuízos da vida social e psíquica dos sujeitos, e exige tratamento médico e psicoterápico tal qual a dependência de uso de substâncias químicas. Além do mais, o transtorno é associado a outros transtornos, cada vez mais identificados na atualidade, que dizem respeito à capacidade de concentração e dispersão, como o Transtorno de Déficit de Atenção e Hiperatividade (TDAH), Transtorno Depressivo e Ansiedade Social (PICON, et al, 2015). Sintomas de uma cultura que promove o déficit de atenção e 
estabelece a hiperatividade como norma de desempenho social. Destaque-se que desde o início da primeira infância, os bebês são expostos aos esquemas de atenção e dispersão provindos das imagens televisivas e outras tecnologias (TÜRCKE, 2016).

Tal situação de dependência de tecnologia compõe a condição contemporânea de uma organização social cujos seus partícipes têm os sentidos extremamente excitados pelos aparatos tecnológicos. Condição que Türcke (2010a), em diálogo com os autores da Teria Crítica da Sociedade e com a Psicanálise de Freud, analisa e, a partir disso, ressalta que o vício, inclusive o do audiovisual, já é um sintoma de abstinência. Quando o que é desejado é negado aos indivíduos, a saber: um estado de bem-estar, em que a sobrevivência (física e social) não esteja constantemente ameaçada, a pulsão se desloca silenciosamente para algo que realiza, parcial e falsamente, aquilo que está obstado. É desse modo que o vício realiza o fetichismo. É desse modo que a realização da vida com base na felicidade da amizade e do amor é fetichizada hoje em dia, por meio do prazer mais facilmente acessível: o virtual (TÜRCKE, 2010a). Sobre a busca por prazeres substitutos, Türcke (2010a, p. 288) diz:

Às satisfações substitutivas, que são procuradas pela vida pulsional desde tempos imemoriais, pertence o contentar-se com estados nos quais o prazer ainda está em seus estágios iniciais, fato este que é expresso no sentido original da palavra "virtual". Virtual significa "a força ou a possibilidade para o existente". O que é possível não corresponde ainda ao real, mas também não é um nada. As possibilidades existem, já têm um grau de realidade consciente. (TÜRCKE, 2010a, p. 288, aspas no original).

Para compreendermos as consequências para a forma de operar do pensamento das crianças e para os fenômenos ligados aos impactos da realidade virtual, basta a observação do comportamento inquieto, incapaz de concentração nas atividades e interação com as outras crianças, que buscam constantemente novos estímulos nos objetos e espaços sem, contudo, se satisfazerem com nada. Em última instância, comportamentos opostos à movimentação propícia para o corpo realizar experiências no tempo e espaço.

De qualquer modo é mais que notável que crianças e jovens hiperativos, os quais no mundo real procedem como se estivessem perdidos, orientam-se bem nos computadores e se movimentam nos jogos online com uma segurança na qual não dispõem na assim chamada 'primeira 
realidade', no cotidiano da vida. (BERGMANN, apud TÜRCKE, 2010, p. 309 , grifo e aspas no original).

Com base em tais entendimentos acerca da relação entre o real e o virtual na infância, toma-se como exemplo analítico a contraposição da teoria do jogo de Huizinga (1938/1999) e as teorias atuais, ainda incipientes, sobre as potencialidades dos jogos eletrônicos.

\section{o sagrado no jogo e a tecnologia consagrada na infância}

Se a esfera do lúdico, cujo principal representante é o jogo, é para Adorno (1970/1988) a forma da repetição que empobrece a arte, restringindo-a a um ritual regressivo de adesão aos momentos práticos aos quais ela poderia se opor, na infância ele reconhece que por meio do jogo a criança alcança a percepção das contradições da realidade. Assim, "o jogo é a defesa delas [das crianças]" (ADORNO, 1951/1992, p. 200).

Embora Adorno (1970/1988) considere que Huizinga (1938/1999), com sua obra Homo Ludens, colocou a categoria sociológica do jogo no centro da estética, por seu momento de recusa da racionalidade instrumental (de meios determinados para os devidos fins), também criticou o caráter de abstração que Huizinga concede ao distanciamento entre o jogo e a práxis da autoconservação na arte. A crítica de Adorno (1970/1988) incide, mais especificamente, sobre a desqualificação da contrariedade que a arte mantém como procedimento e que Huizinga não difere dos jogos dos animais, das crianças e dos primitivos e, também, sobre a perda da materialidade em relação ao surgimento da linguagem humana, por não ter sido considerada a necessidade prática de seu desenvolvimento. Portanto, no que diz respeito à relação apresentada por Huizinga (1938/1999) entre o jogo e os aspectos que caracterizam a razão outra da infância, que interessa a este trabalho, parece possível dizer que Adorno, assim como seus interlocutores Freud e Benjamin, ao considerar a repetição e a imaginação como os motores do jogo e das brincadeiras na infância assumiu o lado verdadeiro da teoria do jogo em Huizinga.

Huizinga (1938/1999) coloca o jogo entre as atividades que constituem a vida humana, não apenas como uma das manifestações culturais, mas como um 
elemento espiritual e histórico - sagrado - que constitui o caráter lúdico da cultura. Sua essência reside no divertimento, na capacidade de fascinar, por isso possui uma significação primária que "se baseia na manipulação de certas imagens, numa certa "imaginação" da realidade (ou seja, a transformação desta em imagens)" (HUIZINGA, 1938/1999, p. 7, aspas e parênteses no original).

Nas sociedades primitivas o jogo está presente tanto nas crianças como nos animais, e nele estão contidas todas as características lúdicas como: “ordem, tensão, movimento, mudança, solenidade, ritmo, entusiasmo" (HUIZINGA, 1938/1999, p. 21). Em uma fase posterior da sociedade, a partir do desenvolvimento da expressão verbal, o jogo assume uma forma poética ao participar de uma expressão da vida ou da natureza. Pode-se ler em Huizinga (1938/1999):

\begin{abstract}
O que era jogo desprovido de expressão verbal adquire agora uma forma poética. Na forma e na função do jogo, que em si mesmo é uma entidade independente, desprovida de sentido e de racionalidade, a consciência que o homem tem de estar integrado numa ordem cósmica encontra sua expressão primeira, mais alta e mais sagrada. Pouco a pouco o jogo vai adquirindo a significação de ato sagrado. $\mathrm{O}$ culto vem-se juntar ao jogo; foi este, contudo, o fato inicial. (HUIZINGA, 1938/1999, p. 21).
\end{abstract}

Na teoria de Huizinga (1938/1999), o jogo marca as grandes atividades arquetípicas da sociedade humana. Assim, a linguagem, o mito, o belo, o pensamento e sua tensão entre a seriedade e a "não seriedade" estão ligados a uma dinâmica essencial do jogo. Portanto, o jogo possui uma independência conceitual que o coloca para além de categorias estabelecidas entre o bem e o mal, a sabedoria e a loucura, a verdade e a falsidade e "embora seja uma atividade não material, não desempenha uma função moral, sendo impossível aplicar-lhe as noções de vício e virtude" (HUIZINGA, 1938/1999, p. 9). Desse modo, Huizinga (1938/1999) ressalta a necessidade de distinguir o conceito de jogo das demais formas de funcionamento do pensamento, ainda que reconheça a impossibilidade de uma definição exata sobre o tema.

O que interessa ressaltar é o caráter sensível dessa forma de funcionamento do pensamento característico na infância que se aproxima do sagrado via imaginação, via "evasão da vida "real" para uma esfera temporária de atividade com orientação própria. Toda criança sabe perfeitamente quando está 
"só fazendo de conta" ou quando está "só brincando"" (HUIZINGA, 1938/1999, p. 11, aspas no original). Nisso reside a seriedade do jogo, no fato de sua experiência se pautar pelas regras da brincadeira, da imaginação, estabelecendo um compromisso unicamente com o prazer de participar. A seriedade do jogo, por ser envolta pelo entusiasmo, eleva-o de sua suposta condição de inferioridade diante da superioridade da realidade da vida e o torna capaz de "absorver inteiramente o jogador" (HUIZINGA, 1938/1999, p. 11).

O empenho entusiasmado dispensado ao jogo não se vincula a nenhum interesse para além do próprio jogo. Sua finalidade em si mesmo interrompe a esfera da vida "comum" e se inscreve como um intervalo na vida cotidiana que possibilita ampliar as necessidades e as satisfações dos indivíduos e da sociedade, firmando-se dentre as manifestações sociais como função cultural. Nesse sentido, Huizinga (1938/1999) compreende o jogo como pertencente "em todas as suas formas mais elevadas, ao domínio do ritual e do culto, ao domínio do sagrado" (HUIZINGA, 1938/1999, p. 12).

Outra característica do jogo que as crianças podem reconhecer em suas brincadeiras imaginativas se refere ao caráter de isolamento e de limitação que circunscreve o jogo num tempo e num espaço próprios. Circunscrito à limitação temporal do jogo, Huizinga (1938/1999) o associa a possibilidade de se fixar num espaço específico, constituindo um fenômeno cultural que pode ser transmitido e conservado pela memória. Desse modo, o jogo conquista a configuração de tradição a ser repetido como mistério composto internamente por elementos que se repetem e se alternam. "Em quase todas as formas mais elevadas do jogo, os elementos de repetição e alternância (como no refrain) constituem como que o fio e a tessitura do objeto" (HUIZINGA, 1938/1999, p. 13, parênteses e grifo no original).

Se a repetição está associada ao tempo específico do jogo, também se associa ao espaço delimitado pelo seu contexto, uma vez que ao se circunscrever num campo determinado, seja ele material ou imaginário, as condições para que o jogo aconteça serão repetidas, ao menos em grande parte. Essas condições de tempo e espaço diferenciados são parte daquilo que torna o jogo algo especial, 
com características que se governam por uma ordem específica capaz de se ordenar a si mesmo e de introduzir "na confusão da vida e na imperfeição do mundo uma perfeição temporária e limitada, [o jogo] exige uma ordem suprema e absoluta: a menor desobediência a esta "estraga o jogo", privando-o de seu caráter próprio e de todo e qualquer valor" (HUIZINGA, 1938/1999, p. 13, aspas no original).

Nesse conjunto de características que movimentam a essência do jogo é que reside o seu poder de "fascínio", por meio de sua capacidade de envolver os sujeitos num ritmo e harmonia especiais. Tal essência do fascínio sagrado, Huizinga (1938/1999) reconhece como elemento do domínio da estética por sua capacidade de resguardar oposições como: "tensão, equilíbrio, compensação, contraste, variação, solução, união e desunião" (HUIZINGA, 1938/1999, p. 13). Contudo, sem perder as potencialidades de cada uma das forças. Ao contrário, o elemento da tensão lança o jogador ao enfrentamento de suas condições para lidar com as regras do jogo. É na tensão com as regras que o jogador é impulsionado por suas qualidades e potencialidades e, disto, depende sua atuação no jogo. Ou seja, as regras que dirigem o jogo, cujo alicerce é a imaginação ordenadora criada no campo do "círculo mágico", suscitam que o jogador participe da magia fazendo uso de suas potencialidades.

Na análise de Huizinga (1938/1999) as capacidades do jogador "em jogo" indicam um movimento de compartilhamento de valores que tensiona o particular e o universal de modo muito específico, segundo o qual a obediência e a disciplina, por exemplo, serão acordadas pelos partícipes. Tal acordo entre os jogadores se manifestam por: "sua força e tenacidade, sua habilidade e coragem e, igualmente, suas capacidades espirituais, sua "lealdade". Porque, apesar de seu ardente desejo de ganhar, deve sempre obedecer às regras do jogo" (HUIZINGA, 1938/1999, p. 14, aspas no original).

Dentre as principais características que Huizinga (1938/1999) apresenta como essencialmente concernentes ao jogo e, nesse sentido, ao seu caráter sagrado que opera a razão cultural, ressalta-se ainda a representação que, ao possibilitar que o indivíduo se torne outro, entrelaça todas as demais características 
mencionadas acima por sua capacidade de "concretizar" o transporte à outra dimensão, que não àquela que a realidade impõe. Na representação os elementos primordiais são a imaginação e a mimese e ambos impulsionam à crença na realização da aparência. Essas faculdades da infância sustentam a representação que se exibe por meio do ritual e do culto, assim, confirmam a memória do ato sagrado na essência do jogo.

As colocar o jogo na esfera do sagrado Huizinga (1938/1999) parece ter contribuído para a compreensão não apenas de uma atividade que está entrelaçada ao desenvolvimento da sociedade, tanto no âmbito do particular como no âmbito do universal, mas também contribui para a compreensão dessa razão outra que se estabelece no interior do jogo e que convive com as necessidades impostas pela vida cotidiana, firmando a tentativa de abrir passagens para uma extra realidade. Uma razão da ordem da imaginação que liga "a criança, o poeta e o selvagem" (HUIZINGA, 1938/1999, p. 30). Resta perguntar em que medida tal ligação, que remete à possibilidade de reconciliação com a natureza, pode ser localizada atualmente nos jogos infantis.

Ressalta-se que as análises de Huizinga (1938/1999) permitem o entendimento de que tais componentes essenciais do domínio do sagrado - via jogo - vêm sofrendo inversões e se distanciando da racionalidade que se firmou a partir do momento histórico em que o mito foi negligenciado na razão esclarecida. Pode-se ler em Huizinga: “O homem moderno, graças à sua sensibilidade estética, conseguiu aproximar-se desses domínios muito mais do que o homem "esclarecido" do século XVIII" (HUIZINGA, 1938/1999, p. 30, aspas no original).

Do contexto esclarecido do século XVIII até os jogos que habitam a infância atual parece ser necessário, ao menos, levantar algumas questões para evitar o risco de corroborar os discursos que, na tentativa de difundir as novas formas de jogos destinados às crianças de hoje, desprezam que a versão do "sagrado" nos tempos tecnológicos foi institucionalizada pela indústria do entretenimento em favor da manutenção do sistema econômico capitalista, deixando em segundo plano as possibilidades de vinculação afetiva que o contato entre as crianças nas brincadeiras pode suscitar. 


\section{o exemplo do jogo eletrônico}

A contraposição entre os aspectos do sagrado presentes no ato de jogar dos humanos e a mediação técnica dos jogos eletrônicos possibilita a compreensão de um contexto da infância atual em que a brincadeira e o jogo se encontram em grande medida atravessados pelos meios tecnológicos e suas dinâmicas específicas. Em tal cenário, o jogo eletrônico ocupa um lugar crescente na vida cotidiana das crianças, marcando-a em suas dimensões reais, principalmente, na administração do tempo e, nisso, naquela que extrapola a realidade, na virtualidade das faculdades do pensamento.

Com base no entendimento de Huizinga (1938/1999) acerca do sagrado como um "lugar" com características superiores, mas também ambíguas às da vida cotidiana quanto ao espaço, ao tempo e aos movimentos específicos que marcam a natureza dos jogos, o exame das permanências e das rupturas de tais características nos jogos atuais possibilita a compreensão dos aspectos dessa nova brincadeira infantil. Ou pelo menos, levanta questões acerca das possibilidades advindas com o incontornável acesso aos meios tecnológicos ao especificar uma materialidade, mediada pelas mídias tecnológicas, que suporta os processos de socialização desde a infância.

Parece possível dizer que nas relações estabelecidas a partir dos jogos eletrônicos a criança ocupa lugar central na configuração tecnológica atual, contudo, alude-se se tais relações apresentam mudanças favoráveis à constituição da subjetividade dos sujeitos e, nisso, aos modos de lidar com a realidade.

Atualmente há no campo educacional, principalmente no escolar, certo entusiasmo em corroborar a ideia de que os jogos eletrônicos parecem resguardar os principais elementos do jogo, mencionados acima, da teoria de Huizinga (1999). Contudo, a materialidade que suporta o jogo em cada período histórico contém suas particularidades, possivelmente, com consequências tanto para o conteúdo formal interno do jogo quanto para a relação estabelecida entre o jogo e o jogador.

O próprio Huizinga (1999) destaca a inversão do caráter lúdico sofrida pelo jogo quando o divertimento deste, que consistia exatamente em sua nãoseriedade, ou melhor, em uma seriedade própria, é organizado, sistematizado e 
regulamentado pelo esporte ou pelos negócios comerciais com consequências que indicam o atrofiamento dos elementos lúdicos entre os indivíduos e suas produções culturais. Embora, os jogos eletrônicos não possam ser reduzidos à organização dos esportes e às mercadorias industriais pela complexidade de seu desenvolvimento tecnológico, que não estava acessível no tempo analisado por Huizinga, mas, justamente por isto, eles são produtos das mudanças ocorridas a partir de tal organização tecnológica na sociedade, expressões da indústria cultural.

Cabe lembrar, antes de tudo, que "os jogos [eletrônicos] são, na realidade, máquinas multifacetadas e complexas" (AARSETH, 2003, p. 12). Ou seja, computadores com sistemas de inteligência artificial, acessíveis a grande parcela da população em idades cada vez mais precoces.

As análises de Huizinga (1999) indicam que os fenômenos sociais de seu tempo que organizavam a produção dos espaços e aspectos lúdicos na cultura já anunciavam a decadência de suas potencialidades. Em suas palavras,

Cada vez mais fortemente se nos impõe a triste conclusão de que o elemento lúdico da cultura se encontra em decadência desde o século XVIII, época em que florescia plenamente. O autêntico jogo desapareceu da civilização atual, e mesmo onde ele parece ainda estar presente tratase de um falso jogo, de modo tal que se torna cada vez mais difícil dizer onde acaba o jogo e começa o não-jogo. (HUIZINGA, 1999, p. 229).

Nesse sentido, para a reflexão acerca das aproximações e rupturas dos elementos que constituem o jogo como lugar do sagrado que dá vazão à imaginação e os jogos eletrônicos é necessária a tentativa de análise do principal elemento de diferenciação dessa materialidade que passou a organizar os elementos lúdicos na cultura, a saber: a mediação tecnológica e, no caso dos jogos eletrônicos atuais, trata-se de uma tecnologia altamente desenvolvida que se coloca como o suporte insubstituível para o jogo e para o jogador.

A construção da infância como uma esfera de subjetividade específica está intrinsecamente ligada à produção de bens materiais, como os livros infantis, os brinquedos, as brincadeiras, as mobílias, que desde a modernidade passaram a mediar a infância (BENJAMIN, 2012). Desse modo, a infância e a produção dos bens de consumo que lhe é dirigida são inseparáveis. Por isso a reflexão acerca dos aspectos que permeiam os jogos eletrônicos não pode se dar senão pela 
compreensão das condições em que tais produções estão inseridas. Em última análise, significa considerar que se, de um modo geral, o jogo "combina, então, em si, as ideias de limites, liberdade e invenção" (CAILLOIS, 1990, p. 11), os jogos eletrônicos são produtos que atualizam tais ideias com os valores de seu tempo.

Autores que advogam a difusão dos jogos eletrônicos como estratégias pedagógicas, como Gee (2009), Jones (2004), Prensky (2010; 2012), assumem, sem restrições, o fato de que os jogos eletrônicos, os videogames, representam uma fonte diversificada de aprendizados, entre eles o treinamento de conteúdos que encontram correspondentes concernentes ao mundo do trabalho. Nas palavras de Prensky (2010),

Assim, por meio de seu divertido jogo de computador, o jovem Tyler aprendeu (sem sequer perceber) os conceitos de cadeia de suprimentos, divisão do trabalho, valor agregado, oferta e procura, estrutura de negócios, controle, pleno emprego, integração vertical, acumulação de bens, construção de capital, corrupção, decisões difíceis, comportamento ético, boa comunicação, solidão da autoridade e compaixão. Ele acumulou, ainda, um útil treinamento em administração, durante o percurso. (PRENSKY, 2010, p. 155. Parênteses no original) ${ }^{10}$.

Não se aprofundará aqui a questão da qualidade de tais aprendizados, mesmo porque isto está explícito, mas parece ser necessário destacar deste tipo de argumento difundido entre autores que abordam a temática dos jogos eletrônicos que o caráter de sagrado presente no jogo, identificado por meio da imaginação, da mimese e da repetição - elementos ordenadores da razão infantil -, parece destoar dos valores mencionados na citação acima acerca dos jogos eletrônicos. Tais valores representam antes a razão exigida aos adultos para a adaptação e autoconservação no capitalismo, historicamente identificados com os do mundo do trabalho.

Certamente, os mundos da brincadeira e do trabalho não se constituem como campos isolados um do outro. No entanto, trata-se de reconhecer que se em algumas brincadeiras, eventualmente, as crianças reproduzem por meio da imaginação e da representação as funções sociais do trabalho, nos jogos eletrônicos o círculo mágico para o qual a criança é chamada foi produzido com uma intenção de estabelecer um comando que obterá uma resposta previamente correspondente

\footnotetext{
${ }^{10} \mathrm{O}$ trecho citado foi extraído de um estudo de caso em que Prensky (2010) analisa o comportamento de uma criança de dez anos com o jogo RuneScape.
}

childhood E philosophy, rio de janeiro, v. 15, jan. 2018, pp. 01- 27 issn 1984-5987 
ao sistema do jogo. Ou seja, a imitação do mundo adulto, que também está presente em outras brincadeiras e jogos, nos jogos eletrônicos é realizada não mais pela criança, mas pelo próprio jogo, que assume como sua função o treinamento dos valores necessários à produtividade em detrimento da experiência imaginativa, bem como a própria transfiguração da realidade virtual no espaço do jogo.

O elemento que determina a forma segundo a qual a realidade virtual se apresentará é o design. Ele é criado com o objetivo de estabelecer estratégias e significados que possibilitem a interação entre o jogador e o sistema operacional do jogo (SALEN; ZIMMERMAN, 2012). Desse modo, num design bem sucedido cada ação terá um resultado correspondente, criado com a finalidade de definir o ambiente do jogo. Ainda que os significados do jogo possam ser revistos na interação entre o jogador e o jogo, de modo geral, o contexto do jogo foi estrategicamente previsto para que seu sistema atinja resultados determinados. Ao que parece, neste contexto todas as imagens já estão definidas para serem assimiladas passivamente pelas crianças. A interação se restringe ao entendimento dos significados e sua aplicação no momento exato.

Segundo pesquisa de Setzer (2014), os jogos eletrônicos mais populares entre as crianças e adolescentes se incluem na categoria de "estímulo-resposta", cujas características são: "ambiente altamente competitivo, altos níveis de violência, de movimentação e de rapidez das imagens exibidas na tela, de atividade de estímulo-resposta e de excitação" (SETZER, 2014, s/p). Não é difícil concluir que, nestes casos, a interação da criança com o jogo se restringe a aplicar os aprendizados dos significados disponíveis para "passar de fase" e continuar a brincadeira.

Desse modo, parece necessário colocar em suspensão nos jogos eletrônicos os elementos que tornam o jogo um lugar de natureza sagrada e lúdica como indicado por Huizinga (1938/1999). Não que tais elementos tenham sido extintos nas relações estabelecidas de fascínio e divertimento, a partir do momento em que o jogador se entrega à atividade de jogar. Mas talvez eles estejam tensionados de modo desproporcional, uma vez que passam antes pelos esquematismos que a 
máquina disponibiliza aos sujeitos. Caminhos que enfraquecem as faculdades sensíveis do pensamento e não contribuem para a superação do enrijecimento que conduz à formação do preconceito e da frieza nas relações humanas, e isso não pode ser deixado de lado nos estudos sobre os jogos eletrônicos, diga-se de passagem, em sua maioria ainda muito superficial.

No que se refere aos processos educacionais, o que se ressalta é que o grande desafio dos tempos tecnológicos reside em recuperar ou incentivar, de alguma forma, aquilo que o jogo pode suscitar: momentos de evasão da realidade por meio do prazer da imaginação e, nesse movimento, vislumbrar possibilidades de elaboração da vida real.

Em especial na infância, as condições para o desenvolvimento das potencialidades lúdicas podem contribuir para o estabelecimento de melhores condições para as relações sociais. Por isso é importante desmistificar o contexto do jogo eletrônico para fazer jus aos seus elementos lúdicos, às brechas que ele pode oferecer para que os indivíduos encontrem meios de acessar sua faculdade imaginativa para resistir às condições que já se faziam presentes no tempo de Huizinga (1999) e que ele assim descreveu:

A vida social moderna está sendo cada vez mais fortemente dominada por uma característica que tem alguma coisa em comum com o jogo e dá a ilusão de um fator lúdico fortemente desenvolvido. Julguei poder dar a esta característica o nome de puerilismo, que me pareceu ser o mais adequado para designar essa mistura de adolescência e barbárie que se tem vindo a estender pelo mundo no decorrer das últimas duas ou três décadas. (HUIZINGA, 1999, p. 228, grifo no original).

Barbárie é o termo que os autores da Teoria Crítica da Sociedade utilizam para dizer de uma situação em que a violência e a regressão psíquica dos indivíduos se sobressaem numa cultura cujas condições materiais estão altamente desenvolvidas. Barbárie e violência são temas que habitam também os círculos mágicos dos jogos e das brincadeiras infantis de todos os tempos, mas que o esforço do pensamento para imaginar e representar pode transfigurar em brechas para a elaboração da realidade. Nos jogos eletrônicos a barbárie e a violência são protagonistas dos jogos mais populares entre as crianças e adolescentes, habitando o lugar prometido para a brincadeira imaginativa. Parece importante saber de que 
forma no contexto virtual tais conteúdos realizam a passagem de volta para a vida real?

Conjecturas sobre como o contato com a realidade está danificado já na infância pela relação com a tecnologia, estabelecendo a busca por satisfação imediata, podem revelar a qualidade da atenção que as crianças recebem nos processos educativos e dar pistas sobre a crescente manifestação de transtornos sócio afetivos, que culminam na preferência por dispor o tempo e o corpo às brincadeiras eletrônicas em detrimento do contato real com as outras crianças.

Se para gerações anteriores é espantoso observar durante os recreios escolares ou reuniões de crianças em momentos de lazer, cada criança entretida com seu smartphone mediando o que poderia ser um jogo compartilhado, não se pode dizer que tal isolamento era inesperado. Adorno e Horkheimer (1947/1985), guardadas as diferenças temporais, mas de modo certeiro, já advertiam para o isolamento, inclusive com a separação física das pessoas, causado pelos meios de comunicação que despontavam nas primeiras décadas da modernidade. Pode ser lido em Isolamento pelos meios de comunicação:

\begin{abstract}
A afirmação que o meio de comunicação isola não vale apenas no domínio cultural. Não apenas a linguagem mentirosa do locutor de rádio se sedimenta no cérebro das pessoas como a imagem da linguagem impede-as de falar umas com as outras, não apenas o louvor da PepsiCola abafa o ruído do desmoronamento dos continentes, não apenas o modelo espectral dos heróis do cinema se projeta sobre o abraço dos adolescentes e mesmo sobre o adultério. O progresso separa literalmente as pessoas. [...] A comunicação cuida da assimilação dos homens isolando-os. (ADORNO; HORKHEIMER, 1947/1985, p. 182-183).
\end{abstract}

Com base em tais entendimentos, parece necessária a consideração de que toda a noção de realidade e, nisso, de contato com os objetos e com os outros, se tornou mais difusa, escorregadia na atualidade virtual. Esperar que a criança saiba discernir entre as amizades das redes sociais daquelas que exigem a presença do corpo, que se afetam um no outro e que compartilham experiências a serem rememoradas um dia, remete mais ao alívio de quem não quer, por estar também perdido, se ocupar com as relações e as questões que a realidade apresenta do que com alguma ingenuidade a respeito da supervalorização dos ambientes virtuais.

No que tange à faculdade da memória, cabe lembrar que a avassaladora "vida virtual" disponibiliza objetos, pessoas, brincadeiras ao alcance do dedo, mas 
também as representações das imagens do mundo, inclusive da imagem transfigurada de si mesmo, e o que merece muita atenção, disponibiliza um registro manipulável de momentos e amizades que podem deixar de existir como se nunca tivessem acontecidos, também, ao alcance do dedo. A tecnologia touch screen pode arquivar ou deletar a interação da criança com sua infância, sua simulação de manifestações de amor e de ódio, seu narcisismo autorizado. Contudo, entregar-se à realidade virtual com vício e sem resistência revela o desejo, ainda que recalcado e anestesiado, de outra vida real em que algum calor afetivo quebre a frieza instaurada, a ponto de marcar a memória com sinais que possam salvar o que se passou e iluminar passagens racionais para a esperança da prometida infância.

\section{referências}

AARSETH, Espen. O jogo da investigação: Abordagens metodológicas à análise de jogos. Caleidoscópio Revista de Comunicação e Cultura. 2003. $2^{\circ}$ sem. N. 4, pp. 9-23. Disponível:http://revistas.ulusofona.pt/index.php/caleidoscopio/article/download/22 36/1753. Acesso em 09/12/2013.

ADORNO, Theodor W. Educação e emancipação. (W. L. Maar, Trad.). São Paulo: Paz e Terra, 1995, 190p. (Obra original publicada em 1971).

. Sobre sujeito e objeto. In Palavras e sinais: modelos críticos 2. (M. H.

Ruschel, Trad.). Petrópolis, RJ: Vozes, 1995a, pp. 181-201. (Obra original publicada em 1969).

- Minima Moralia: reflexões a partir da vida danificada. (L.E. Bicca, Trad.). 2ed. São Paulo: Ática. 1992, 216p. (Obra original publicada em 1951).

Teoria Estética. (Artur Mourão, Trad.). Lisboa, Portugal: Edições 70, 1988. 408p. (Obra original publicada em 1970).

. A Indústria Cultural (A. Cohn, Trad.). In G. Cohn (Org.). Theodor W. Adorno [Coleção Grandes Cientistas Sociais]. São Paulo: Editora Ática, 1986, pp. 92-99. (Obra original publicada em 1963).

ADORNO, Theodor W.; HORKHEIMER, Max. Dialética do esclarecimento: fragmentos filosóficos. (G. A. Almeida, Trad.). Rio de Janeiro: Jorge Zahar, 1985. 223p. (Obra original publicada em 1947) Reimpressão 2006.

BENJAMIN, Walter. Magia e técnica, arte e política: ensaios sobre literatura e história da cultura/ Walter Benjamin. (Sérgio P. Rouanet, Trad.; Prefácio Jeanne Marie Gagnebin). $8^{a}$. Ed. São Paulo: Brasiliense, 2012, 271p.

Rua de Mão Única. (Rubens Torres Filho; José Carlos Martins Barbosa, Trad.; rev. téc. Márcio Seligmann-Silva). 6a Ed. São Paulo: Brasileiense, 2012a. (Obras Escolhidas V. 2).

Rua de mão única Extratos. In Reflexões sobre a criança, o brinquedo e a educação Walter Benjamin. (Marcus Vinícius Mazzari, Trad.) 2a Ed. São Paulo: Editora 34, 2002, pp.103-110. Reimpressão 2011. 
Brinquedos e jogos. In Reflexões sobre a criança, o brinquedo e a educação Walter Benjamin. (Marcus Vinícius Mazzari, Trad.) 2a Ed. São Paulo: Editora 34, 2002a, pp. 95-102. Reimpressão 2011. (Obra Original publicada em 1969).

A doutrina das semelhanças. In Magia e técnica, arte e política: ensaios sobre literatura e história da cultura/ Walter Benjamin. (Sérgio P. Rouanet, Trad.; Prefácio Jeanne Marie Gagnebin). 7ª. Ed. São Paulo: Brasiliense, 1994, 1v., pp. 108-113. 10a Reimpressão 1996. (Texto escrito em 1933).

Sobre alguns temas em Baudelaire. In

W. Benjamin, Charles Baudelaire um lírico no auge do capitalismo. (H. A. Baptista, Trad.). Obras escolhidas vol. III. São Paulo: Editora Brasiliense, 1989, pp. 103-149. (Obra original publicada em 1939).

Infância em Berlin por volta de 1900. In Obras escolhidas V II. São Paulo:

Brasiliense, 1987, pp. 71-142.

CAILLOIS, R. Os jogos e os homens. Lisboa: Portugal, 1990.

CANEVACCI, Massimo. Sociologia da Família. In Dialética da Família Gênese, estrutura e dinâmica de uma instituição repressiva. (Carlos Nelson Coutinho, Trad.). $4^{\mathrm{a}}$ ed. São Paulo: Brasiliense, 1981, pp.210-222. (Escrito originalmente em 1966).

CLAUSSEN, Detlev. Theodor W. Adorno: Uno de los últimos genios. (Vicente Gómez Ibañez, Trad.). València: Universitat de València, España, 2006. 443p.

FREUD, Sigmund. Três ensaios sobre a teoria da sexualidade. In . FREUD, Sigmund Edição Standard Brasileira das Obras Psicológicas Completas. (J. O. A. Abreu, Trad.). Rio de Janeiro: Imago, 1976. V. VII, pp. 118-229. (Obra original publicada em 1905).

GEE, James Paul. Bons videogames e boas aprendizagens. 2009. PDF. Disponível em: https:// periodicos.ufsc.br/index.php/perspectiva/article/viewFile/15838/14515.

Acesso em 11/2016.

HORKHEIMER, Max. Eclipse da razão. (Sebastião Uchoa Leite, Trad.). São Paulo: Centauro, 2002. 187p. (Obra original publicada em 1946).

HUIZINGA, Johan. Homo Ludens o jogo como elemento da cultura. (João Paulo Monteiro, Trad.). São Paulo: Editora Perspectiva, São Paulo - SP, 1999, 243p. (Obra original publicada em 1938).

JONES, Gerard. Brincando de Matar Monstrons: por que as crianças precisam de fantasia, videogames e violência de faz-de - conta. (Ana Ban, Trad.). São Paulo: Conrad Editora do Brasil, 2004.

MARX, Karl. Fetichismo e reificação. In IANNI, O. (Org.). Marx. (R. Sant'Anna, Trad.). (6 ed.). Col. Grandes Cientistas Sociais. São Paulo: Ática, 1988, pp. 159-172. (Obra original publicada em 1867).

PICON F., et al. Precisamos falar sobre tecnologia: caracterizando clinicamente os subtipos de dependência de tecnologia. Revista Brasileira de Psicoterapia. 2015, 17(2), pp. 4460. Disponível em: http://rbp.celg.org.br/detalhe_artigo.asp?id=177. Acesso em 06/02/2017.

PRENSKY, Marc. Aprendizagem baseada em jogos digitais. São Paulo: Editora Senac, São Paulo, 2012.

. Não me atrapalhe, mãe - Eu estou aprendendo: como os vídeos games estão preparando nossos filhos para o sucesso no século XXI- e como você pode ajudar! (Lívia Bergo, Trad.). São Paulo: Phorte, 2010.

SALEN, K.; ZIMMERMAN, E. Regras do jogo: fundamentos do design de jogos. São Paulo: Blucher, 2012.

SALGADO, Mara. ENTRELAÇAMENTO DO AMOR E DO PENSAMENTO NA INFÂNCIA EM THEODOR W. ADORNO: UM ESTUDO SOBRE MIMESE, IMAGINAÇÃO E MEMÓRIA. 2017, pp. 114-124. Tese de doutorado - Curso de PósGraduação em Educação, Departamento de CCE, Universidade Federal de Santa Catarina, Florianópolis, 2017, 152f. 
SALGADO, Mara; FRANCISCATTI, Ketty V. S. Arte, artesanato e trabalho: um estudo acerca dos limites do fazer e criar artesanal. Gerais Revista Interinstitucional de Psicologia.

Vol. 04. N. $02 . \quad 2011$, pp. 284-296. Disponível em http://www.fafich.ufmg.br/gerais/index.php/gerais/index. Acesso em 28/05/2011.

SELIGMANN-SILVA, Márcio. A Atualidade de Walter Benjamin e de Theodor W. Adorno. $2^{\mathrm{a}}$ Ed. Rio de Janeiro: Ed. Civilização Brasileira, 2010. 142p.

SETZER, V. W. Efeitos negativos dos meios eletrônicos em crianças, adolescentes e adultos. São Paulo, 2014. Disponível em: https://www.ime.usp.br/ vwsetzer/efeitosnegativos-meios.html. Acesso em 05/07/2016.

VAZ, Alexandre Fernandez. Educação, experiência, sentidos do corpo e da infância (um estudo experimental em escritos de Walter Benjamin). In Experiência, educação e contemporaneidade. Org. Pedro Angelo Pagni e Rodrigo Pelloso Gelamo. Marília, SP: Poesis, 2010, pp. 35-48.

TÜRCKE, Christoph. Hiperativos! Abaixo a cultura do déficit de atenção. (José Pedro Antunes e Eduardo G. B. Losso, Trad.). São Paulo: Paz e Terra, 2016, 144p.

Filosofia do sonho. (Paulo Rudi Schneider, Trad.). Ijuí: Ed. Unijuí - SC, 2010, 328p. . Sociedade Excitada: filosofia da sensação. (Antônio A. S. Zuin...[et al.], Trad.). Campinas, SP: Editora da Unicamp, 2010a , 323p.

VAZ, Alexandre. Marcas do corpo escolarizado, inventário do acúmulo de ruínas: sobre a articulação entre memória e filosofia da história em Walter Benjamin e Theodor W. Adorno. In. Educação do corpo na escola brasileira. Org. Marcos Aurélio Taborda de Oliveira. Campinas, SP: Autores Associados, 2006, pp. 35-56. Coleção Educação Física dos Esportes. 